\title{
Effect of plant growth regulators on production of alpha-linolenic acid from microalgae Chlorella pyrenoidosa
}

\author{
SUJANA KOKKILIGADDA, BINDIYA PANDEY and SRINIVASA REDDY RONDA* \\ Centre for Bioprocess Technology, Department of Biotechnology, K L E F University, Guntur 522 502, India \\ e-mail: rsr@kluniversity.in
}

MS received 13 October 2016; revised 22 March 2017; accepted 30 May 2017; published online 5 October 2017

\begin{abstract}
The effect of various plant growth regulators (6-benzylaminopurine (BAP), 6-furfurylaminopurine (Kinetin), gibberellic acid (GA3), 1-naphthaleneacetic acid (NAA) and indole-3-butyric acid (IBA)) on the yields of biomass and an essential free fatty acid (alpha-linolenic acid from Chlorella pyrenoidosa) were studied. NAA and BAP showed significant increase of 2.2- (0.2905 to $0.6497 \mathrm{~g} / \mathrm{L})$ and 1.26 -fold $(0.2905$ to $0.3727 \mathrm{~g} / \mathrm{L})$ in biomass yield, respectively. The only plant growth regulators belonging to the group cytokinins (BAP and kinetin) showed prominent rise in the yields of alpha-linolenic acid. BAP and kinetin resulted in 2.94- (371.83 to $1105.93 \mu \mathrm{g} / \mathrm{mL}$ ) and 3.03 -fold (371.83 to $1128.25 \mu \mathrm{g} / \mathrm{mL}$ ) increase in ala yields, respectively, compared with that of control.
\end{abstract}

Keywords. Plant growth regulators; microalgae; Chlorella pyrenoidosa; alpha-linolenic acid.

\section{Introduction}

Alpha-linolenic acid is one of the essential omega-3 fatty acids that is used in treating nervous system disorders, rheumatoid arthritis, renal problems and diabetes [1,2]. It is mainly available in plant sources such as flaxseed (linseed) oil, canola (rapeseed) oil, and soybean oil, as well as in red meat and dairy products. The area of rising interest is the production of such high-value products from microalgae that has many advantages over the conventional sources because of factors such as their high photosynthetic efficiency, more economy, effective culture in lands not suitable for farming, and ability to use seawater. Plant growth regulators are signal molecules that are produced by plants and control a wide range of plant growth and developmental processes at low concentrations. There are different plant growth-regulating hormones that show different effects on plant growth such as reproduction, stimulating defensive responses, development and cell division or seed germination, and inhibiting stem elongation. Certain studies showed that plant growth regulators effect biomass growth rate of certain microalgae [3,4]. Studies conducted by Piotrowska-Niczyporuk on Chlorella vulgaris under different plant growth regulators revealed that cytokinins showed increase in cell number [5]. In this work, Chlorella pyrenoidosa, which is a good source of polyunsaturated fatty acid-alpha-linolenic acid and grows fast, was considered to study the effect of plant growth regulators on the

*For correspondence yield of alpha-linolenic acid production. The plant growth regulators investigated in the study include auxins (naphthaleneacetic acid (NAA) and indole-3-butyric acid) that promote the growth [6], cytokinins (6-benzylaminopurine (6-BAP) and 6-furfurylaminopurine (kinetin)) that enhance cell division [7] and gibberellins (gibberellic acid (GA3)) that have their effect on growth and stem elongation [8].

\section{Materials and methods}

\subsection{Materials}

All the solvents and chemicals used were purchased from Merck India Ltd. Alpha-linolenic acid standard was procured from Sigma Aldrich. Chlorella pyrenoidosa (NCIM Accession No. 2738) was purchased from NCIM, India. Plant growth hormones were bought from Himedia, India.

\subsection{Cultivation of microlagae}

The green microalgae Chlorella pyrenoidosa obtained from NCIM in streaked form was subcultured for inoculums development in $10 \mathrm{~mL}$ Fogg's medium $\left(\mathrm{K}_{2} \mathrm{HPO}_{4}, 0.2 \mathrm{~g} / \mathrm{L}\right.$; $\mathrm{MgSO}_{4}, 0.2 \mathrm{~g} / \mathrm{L} ; \mathrm{CaCl}_{2}, 0.1 \mathrm{~g} / \mathrm{L} ; \mathrm{KNO}_{3}, 2 \mathrm{~g} / \mathrm{L}$ ), which was further scaled up to $100 \mathrm{~mL}, 200 \mathrm{~mL}, 1 \mathrm{~L}$ medium simultaneously. The inoculum thus developed was added at $10 \%$ to the required quantity of medium. The $\mathrm{pH}$ and temperature of the medium was maintained at 7.2 and $25^{\circ} \mathrm{C}$ 
respectively. The microalgal culture was grown for 4 days with aeration rate of $2 \mathrm{lpm}$.

\subsection{Effect of plant growth hormones}

To study the effect of plant growth hormones, gibberellic acid, indole-3-butyric acid, kinetin, 6-benzylaminopurine, 1-naphthaleneacetic acid, at different concentrations ranging from $2 \mathrm{mg} / \mathrm{L}$ to $10 \mathrm{mg} / \mathrm{L}$ each were considered to optimised the concentration of plant growth regulators on ala production, among which $4 \mathrm{mg} / \mathrm{L}$ concentration of all the growth hormones showed significant effect on ala production. Hence, $4 \mathrm{mg} / \mathrm{mL}$ of each hormone were added to different conical flasks containing Fogg's medium and the $\mathrm{pH}$ was adjusted to 7.2 and incubated for 4 days at $25^{\circ} \mathrm{C}$.

\subsection{Harvesting microalgae}

Harvesting of the microlagal culture was done at the end of the growth period by flocculation method [9] using alum (hydrated potassium aluminum sulphate) as the precipitant. Flocculation method was chosen for harvesting as it requires very less energy, time and chemical consumption than other harvesting methods. The clear supernatant obtained after precipitation of algal cells was carefully discarded. The final dewateration of the microalgal slurry settled at the bottom was done by centrifugation. Thermo Sorvall Xtr Refrigerated Centrifuge 75004521 model was used, and the operation parameters include $7000 \mathrm{rpm}$ for $5 \mathrm{~min}$. The wet biomass pellet thus obtained was oven dried at $100^{\circ} \mathrm{C}$ overnight. The dried biomass was ground to a fine powder using mortar and pestle and preserved for future investigation.

\subsection{Fatty acids analysis by gas chromatography}

The sample preparation for GC analysis was according to Lepage and Roy [10]. Methylation was done by addition of $20 \mathrm{~mL}$ of freshly prepared transesterification reagent (methanol/acetyl chloride, 95:5 v/v) to $100 \mathrm{mg}$ of biomass sample in a crew-capped bottle and heated at $80^{\circ} \mathrm{C}$ for $1 \mathrm{~h}$. At the end of the incubation period, 2 to $3 \mathrm{~mL}$ water was added to the bottle to stop the reaction. Methylated FFAs were extracted by addition of hexane. Hexane phase was separated and evaporated to $1 \mathrm{~mL}$ for GC analysis. Total fatty acids were estimated using gas chromatography (Thermo Scientific 8610) with a flame ionising detector. A fused silica capillary column with a cyanopropyl polysiloxane stationary phase equivalent to $70 \%$ cyanopropyl (SGE, BPX-70, $25 \mathrm{~m}$ length $\times 0.32 \mathrm{~mm} \mathrm{ID} \times$ $0.25 \mu \mathrm{m}$ film thickness) was employed for the detection of fatty acid methyl ester (FAME). The GC parameters included in table 1 .
Table 1. Gas chromatography parameters for free fatty analysis.

\begin{tabular}{|c|c|}
\hline GC Parameter & Value \\
\hline $\begin{array}{l}\text { Temperature of injection and } \\
\text { detector ports }\end{array}$ & $240^{\circ} \mathrm{C}$ and $250^{\circ} \mathrm{C}$ \\
\hline Injection volume & $0.5 \mu \mathrm{L}$ \\
\hline Carrier gas & Nitrogen \\
\hline Initial temperature & $100^{\circ} \mathrm{C}, 1 \mathrm{~min}$ hold \\
\hline Ramp at & $\begin{array}{c}10^{\circ} \mathrm{C} \min ^{-1} \text { until } 180^{\circ} \mathrm{C} \text { with } \\
1 \text { min hold }\end{array}$ \\
\hline Ramp at & 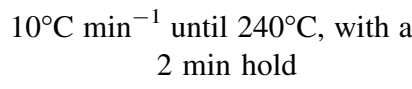 \\
\hline
\end{tabular}

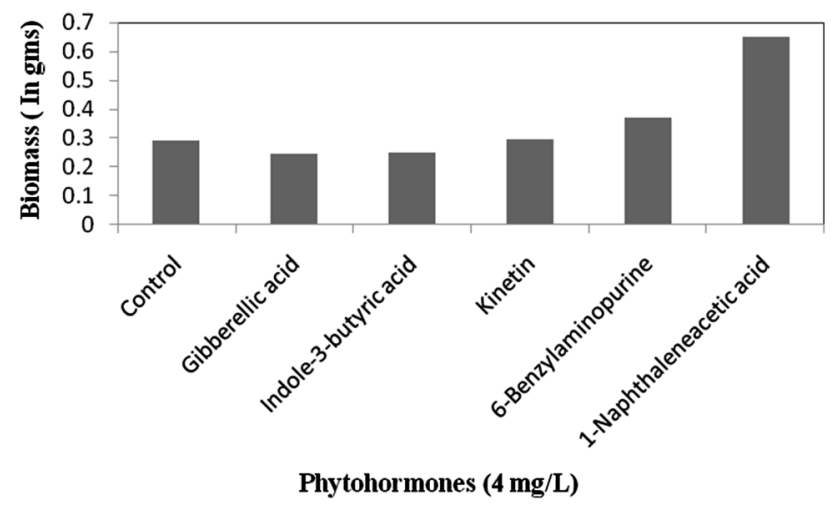

Figure 1. Effect of phytohormones on biomass yield of Chlorella pyrenoidosa.

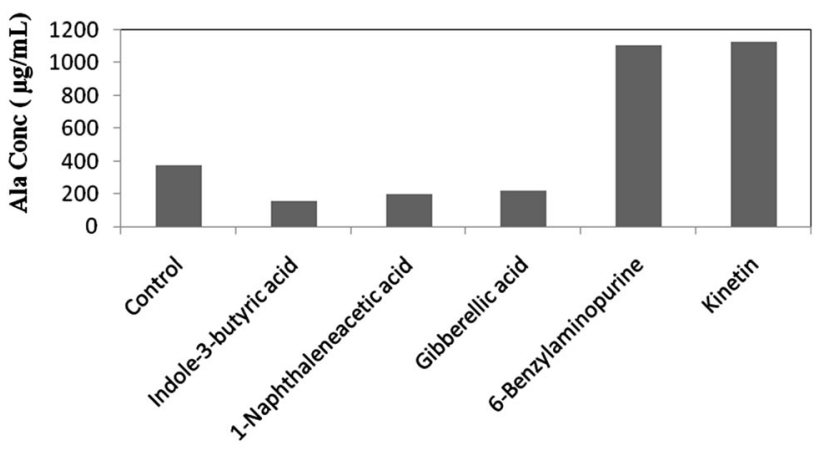

Phytohormones (4 mg/L)

Figure 2. Effect of phytohormones on alpha linolenic acid yield in Chlorella pyrenoidosa.

\section{Results and discussion}

Among all the growth hormones except 1-naphthaleneacetic acid (NAA) and 6-benzylaminopurine (6-BAP), others did not show any effect on the biomass yield of Chlorella pyrenoidosa. NAA showed 2.2-fold (0.2905 to $0.6497 \mathrm{~g} / \mathrm{L}$ ) increase in biomass production compared with 

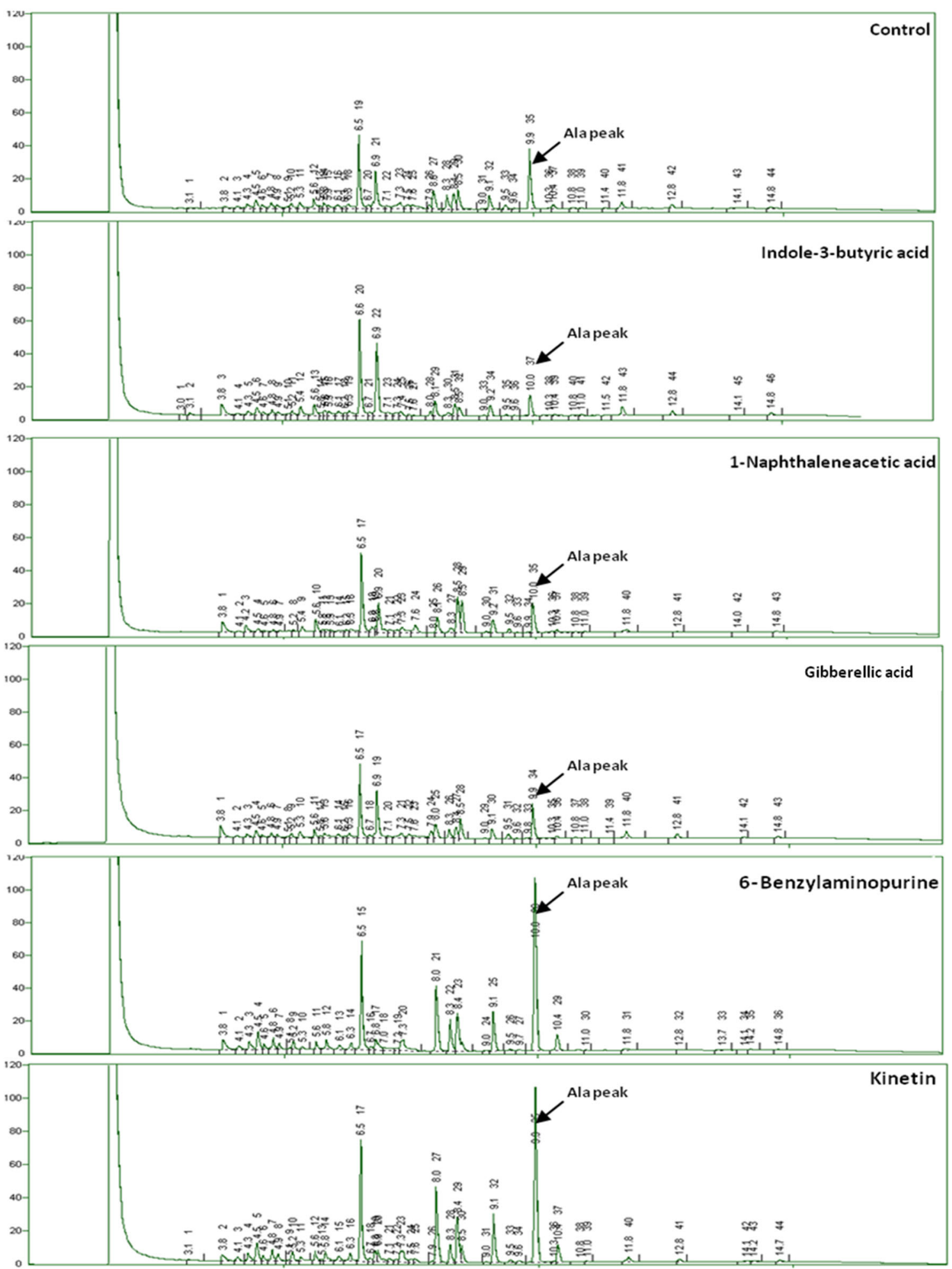

Figure 3. Comparision of gas chromatograms showing the effect of various phytohormones on alpha linolenic acid concentration in Chlorella pyrenoidosa.

that of control, whereas BAP resulted in 1.26-fold (0.2905 to $0.3727 \mathrm{~g} / \mathrm{L}$ ) increase. NAA and IBA both belong to auxins, which show great effect on growth rate of microalgae [4], but in this case only NAA showed significant increase and IBA showed slight decrease $(0.2905$ to $0.2505 \mathrm{~g} / \mathrm{L})$ in biomass yield. BAP and kinetin belonging to cytokinins group of plant growth regulators promote cell division in plants have a varying effect on the 


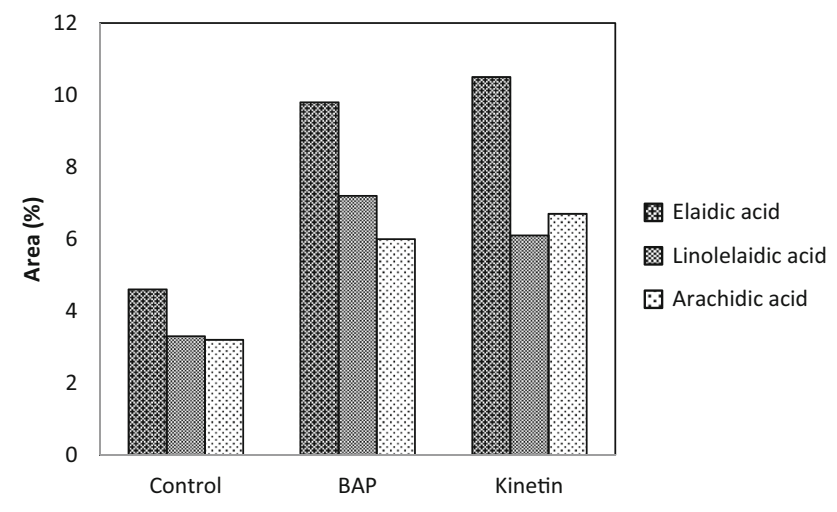

Figure 4. Increase in the area percentage of free fatty acids other than alpha linolenic acid in Chlorella pyrenoidosa when treated with cytokinins (BAP and Kinetin).

growth of Chlorella pyrenoidosa; BAP showed good increase in biomass as mentioned earlier, whereas kinetin almost did not show any effect. Gibberellic acid, whose one of the functions is to induce cell elongation as well as seed germination in plants, did not show any positive effect on biomass enhancement, as it led to decrease $(0.2905$ to $0.2454 \mathrm{~g} / \mathrm{L}$ ) in biomass production compared to that of the control. Figure 1 provides effect of plant growth regulators on biomass yield. Thus, certain plant growth regulators (NAA, BAP) show enhancing effect on biomass production in Chlorella pyrenoidosa. Addition of these hormones to media is more cost-effective than other carbon source for more biomass yields.

The free fatty acid-alpha-linolenic acid (ala) yield was significantly affected by a specific group of plant growth regulators used in the study called cytokinins, that is, BAP and kinetin. BAP resulted in 2.94-fold (371.83 to $1105.93 \mu \mathrm{g} / \mathrm{mL}$ ) and kinetin in 3.03-fold (371.83 to $1128.25 \mu \mathrm{g} / \mathrm{mL}$ ) increases in ala production in Chlorella pyrenoidosa. The growth hormones, auxins (IBA (371.83 to $151.81 \mu \mathrm{g} / \mathrm{mL}$ ), NAA ( 371.83 to $200.73 \mu \mathrm{g} / \mathrm{mL}$ )) and gibberellins ( 371.83 to $220.04 \mu \mathrm{g} / \mathrm{mL}$ ) used showed decrease in alpha-linolenic acid production. The effect of various plant growth regulators on alpha-linolenic acid production is shown in figure 2. Figure 3 gives a comparative picture of the fatty acid profiles of Chlorella pyrenoidosa treated with different growth hormones.

The fatty acid profiles of microalgae treated with various plant growth regulators showed almost the same profiles when compared with that of control except BAP and kinetin. But cytokinins (BAP and kinetin)-treated profiles showed significant rise in peak area of fatty acids other than alpha-linolenic acid, which include elaidic acid, linolelaidic acid and arachidic acid. The increase in the area percentage of these fatty acids is given in figure 4 . Of the three fatty acids, the significant one is arachidic acid, as it is used to produce photographic materials, detergents, lubricants, softener agents, dispersing agents and food packaging. It is also used to manufacture pharmaceuticals as nutritional supplements and as an emollient and thickening agent in cosmetics.

\section{Conclusion}

In this study, it was concluded that growth hormones showed significant effect on both biomass and the essential fatty acid-alpha-linolenic acid yields in Chlorella pyrenoidosa. NAA and BAP showed significant increase of 2.2- and 1.26-fold in biomass production. BAP and kinetin resulted in 2.94- and 3.03-fold increase in ala yield. Thus, BAP that is showing prominent effect on both biomass and ala yield can be selected as the best phytohormone for enhancing ala production in Chlorella pyrenoidosa.

\section{References}

[1] Hennessy A A, Ross R P, Devery R and Stanton C 2011 The health promoting properties of the conjugated isomers of $\alpha$ linolenic acid. Lipids 46: 105-119

[2] Aliza H S, Michael A C and Ram R 2011 Update on alphalinolenic acid. Nutr. Rev. 66(6): 326-332

[3] Bajguz A and Czerpak R 1996 Effect of brassinosteroids on growth and proton extrusion in the alga Chlorella vulgaris Beijerinck (Chlorophyceae). Plant Growth Regul. 15: 153-156

[4] Hunt R W, Chinnasamy S, Bhatnagar A and Das K C 2010 Effect of biochemical stimulants on biomass productivity and metabolite content of the microalga, Chlorella sorokiniana. Appl. Biochem. Biotech. 162(8): 2400-2414

[5] Piotrowska-Niczyporuk A, Bajguz A, Zambrzycka E and Godlewska-Żyłkiewicz B 2012 Plant growth regulators as regulators of heavy metal biosorption and toxicity in green alga Chlorella vulgaris (Chlorophyceae). Plant Physiol. Biochem. 52: 52-65

[6] William D Teale, Ivan A Paponov and Klaus Palme 2006 Auxin in action: signalling, transport and the control of plant growth and development. Nat. Rev. Mol. Cell. Biol. 7: 847-859

[7] Gaspar T, Kevers C, Penel C, Greppin H, Reid M D and Thorpe T A 1996 Plant hormones and plant growth regulators in plant tissue culture. In Vitro. Cell. Dev. Biol.-Plant 32: 272-289

[8] Gupta R and Chakrabarty S K 2013 Gibberellic acid in plant: still a mystery unresolved. Plant Signal Behav. 8(9): e25504

[9] Vandamme D, Foubert I and Muylaert K 2013 Flocculation as a low-cost method for harvesting microalgae for bulk biomass production. Trends Biotechnol. 31(4): 233-239

[10] Lepage G and Roy C C 1986 Direct transesterification of all classes of lipids in a one-step reaction. J. Lipid Res. 27(1): 114-120 